\title{
Predicting Trend of Stock Prices by Developing Data Mining Techniques with the Aim of Gaining Profit
}

Seyed Saman Emami*

Faculty of Industrial and Mechanical Engineering, Qazvin Branch, Islamic Azad University, Qazvin, Iran

\begin{abstract}
In financial markets, for the purpose of forecasting the future trend of stock prices, technical analysis tools are used, with the tools of the analysis including harmonic patterns, time tools and technical indicators. Due to the fact that technical indicators play a very important role in predicting the future trend, they also confirmed the results of other technical models and instruments, so these indicators have a great importance in technical analysis. Traders of financial markets are faced with a wide range of these technical indicators, so that the accuracy of each of them is not specified, as well as many traders which used them tactfully and effortlessly, so, in this study, using individual machine learning algorithms, we determined the significance of each of these indicators. Also, the ensemble learning algorithm has been developed with the goal of increasing predictive efficiency. In the forthcoming study, before entering into the machine learning discussion, 12 popular indicators are ranked by market participants by the VIKOR method. Also, with using Decision Tree, Artificial Neural Network, Support Vector Machine and Logistic Regression, the importance of each indicator based on precision Specified nose and output values have been calculated. Further, the ensemble learning model has been developed with the aim of increasing the efficiency and accuracy by the optimization technique and the results of this model have been compared with the Weighted Majority Voting method. The results showed that OBV, $\mathrm{CCl}$ and EMA indicators are very important. Also, the results of machine learning indicated the superiority of the results of the SVM method in prediction accuracy.
\end{abstract}

Keywords: Stock exchange; Machine learning; Technical indicator; Ensemble learning; VIKOR; Optimization

\section{Introduction}

Due to the wide range of financial markets and their attraction for investment, so many people, even with little knowledge, can invest in this area. Gaining profit in financial markets requires an analysis of the price trend of financial instruments and the determination of their inherent value.

In general, there are two types of analysis in the financial markets for entering or exiting / trading positions, fundamental analysis and technical analysis. Fundamental analysis includes analysis of financial reports and financial health of the company, management and competitive advantages, competitors, and relevant markets. Analysts in fundamental analysis are looking for large factors that affect the price of financial instruments.

In contrast to fundamental analysis, there is technical analysis. This method tries to predict future price changes by studying market behaviors by studying price charts, moving average prices, trading volumes, open trading volumes, pattern formation, market fluctuations, and other technical indicators. In some cases, Technical analysis is also expected to estimate future prices. Technical analysis is a common practice in many financial markets.

One of the problems of independent investors and market analysts is that in technical analysis, they are faced with a wide range of indicators for predicting prices, that the significance and precision of prediction of each one not clear, and most analysts, according to their trading habits use a series of specific indicators to predict price trends and transaction situations that are not necessarily of high precision. Also, given the limited time to identify the appropriate situations for a transaction, they have to quick decision-making. The randomness of the price changes and the presence of a large number of indicators available for Technical Analysis formed the main idea of this study, which primarily classifies the used technical indicators among the indicators used in the financial markets. Then, the significance of each of these indicators in determining the future trend of prices is determined by using machine learning models. Ensemble learning was also developed by using optimization methods to improve learning efficiency and increase prediction accuracy and reduce computational time.

During this research, another important question was raised about how we can consider the market's psychological and emotional impact as an input variable in machine learning models, so the price changes of underlying commodities, whose trend of price change is commensurate with the global markets, has been noticed. The average changes in the price of crude oil and gold have correlated with stock price changes, so this average was considered as one of the input variables to determine the significance of global market changes in predicting the future trend of the financial instrument.

There have also been many studies on technical analysis and machine learning. The term technical analysis is a title for a class of particular analytic methods which is trying to predict the upcoming trend by looking at the past behavior of stock price. Technical analysts believe that future changes in supply and demand can be predicted by price charts. Approximately since 1800, there have been methods of trading under the name of technical analysis. In the United States, the

${ }^{*}$ Corresponding author: Seyed Saman Emami, Faculty of Industrial and Mechanical Engineering, Qazvin Branch, Islamic Azad University, Qazvin, Iran, Tel: +9828-33665275; E-mail: saman.emami@gmail.com

Received October 01, 2018; Accepted December 08, 2018; Published December 22, 2018

Citation: Emami SS (2018) Predicting Trend of Stock Prices by Developing Data Mining Techniques with the Aim of Gaining Profit. J Account Mark 7: 304. doi: 10.4172/2168-9601.1000304

Copyright: @ 2018 Emami SS. This is an open-access article distributed under the terms of the Creative Commons Attribution License, which permits unrestricted use, distribution, and reproduction in any medium, provided the original author and source are credited. 
history of using technical analysis in the stock market is as old as the market itself, and many of these methods, which are used today, go over 60 years of their use [1]. The academic professors' view of technical analysis was quite negative by the year 2000, as an example [2] it says that the historical price and volume data cannot predict future price changes. He describes his proposals as the form of a random step theory, it means the best way to invest in the market is to buy various securities in a long time. In the years to come, with a more detailed modeling of technical analysis and better utilization of its foundations, some researches differed from technical analysis. So that Brock Lakonishok in his paper [1], using statistical tests, it was concluded that technical analysis helps to predict stock price changes. According to studies conducted until 2004, it has been shown that of 95 studies conducted in 56 studies resulted in a positive evaluation of technical analysis, 20 studies leading to a negative assessment of technical analysis and other studies have also reached a neutral conclusion regarding to efficiency of technical analysis [3]. In recent years, many studies have been carried out the using of machine learning to increase the accuracy of price prediction, increase in returns, reduce risk and examine the predictive power of rules and indicators of technical analysis. Charkha [4] conducted a study on stock price prediction and trend using the neural network. In his study, the starting price of the share at the first day of the next week and the stock price trend (in two classes of zero or one) is predicted using the neural network classification model. Training data is the close price for the first 4 days of the week. To predict the trend, all prices are converted into positive and negative classes.

Teixeira and de Oliveira [5] predict stock price trends with using the technical analysis and K-NN classification model. They offered a stock trading system based on end prices and trading volumes. This trading system has been compared to the traditional system (purchasemaintenance and sales) and the results have shown that this method is more efficient. Finally, there are two classes of purchase or sale.

A multiple-kernel support vector regression approach for stock market price forecasting, is the title of Yeh and Huang [6] study. A proposed method is a two-step learning algorithm that combines several Kernel matrixes for the SVM model. The learning algorithm produces the best optimization and reflection of Lagrange coefficient gradient and optimal kernel weights.

Son and Noh [7] did a study with the title of the Forecasting trends of high-frequency KOSPI200 index data using learning classifiers. In their study, five minutes later of the KOSPI200 index is predicted with binary classification. The inputs of the model included the RDPMA-EMA-DISP-EDISP-OSCP-EOSCP-RSI indicators and the data was related to the KOSPI200 index value for a week. The results of the classification models are compared with three different sets of data. The results indicate the superiority of the SVM method when no dimensional reduction has been made.

Booth and Gerding [8] Provided an expert system that, with using machine learning techniques, predicted price efficiencies in seasonal periods, and based on a well-deployed trading strategy, they also used different regression and different weighting techniques. Their results showed that the random forest, in comparison with other sets of techniques, has better performance both in terms of efficiency and predictive power. The inputs of the model included the closing prices for the first four weeks of the NSE (New York Stock Exchange) stock market. Post-test data used for direct network training achieved a 100\% prediction score. While in a radius-based network it only reached $80 \%$.

Stock Trend Prediction with Technical Indicators using SVM is the title of Di [9] study. His focus was to predict the stock trend of a company in four periods. He chose the technical analysis indicators after studying the price data at time $t$ and period $n$. Also, the data was related to the stock prices of the Apple, Amazon and Microsoft companies.

A Naïve SVM-KNN based stock market trend reversal analysis for Indian benchmark indices is the title of Nayak, Mishra [10] study. In their study, the indices of the Indian stock market were predicted with using the support vector machine and $\mathrm{K}$ nearest neighbor. The data was related to the historical values of CNX and BSE indices, and the close price trends along with market fluctuations have been used as SVM and KNN variables. They combined the methods of SVM and KNN, so that the profit and loss was predicted by the SVM kernel function, and the SVM output was used to improve the KNN to find the best training set for prediction.

Patel and Shah [11] developed Predicting stock and stock price index movement using trend deterministic data preparation and machine learning techniques. Their focus was on predicting the stock movements and stock indexes. They performed predictions using ANN, SVM, Random Forest and Naive-Bayes. Classification was done in two classes (Positive and negative), which indicates a bullish or bearish trend in the price trend. Finally, the accuracy and performance of the proposed classification methods was compared. The inputs of the model included the technical indicators, a simple moving average of ten days, weighted moving average, Momentum, Stochastic, RSI, MACD, William R\% and CCI. Also the historical data was from 2003 to 2012 and collected from the NIXTEX, NIFTY, S\&P BSE Sensex, Infosys Ltd from the Indian stock market. To evaluate and compare the accuracy of the classification methods, the F-measure was considered. The results after the evaluation showed that the Random Forest model had the highest accuracy and the naive-Bayes model had the least accuracy. The ANN model also had less performance in learning from the other four models.

Patel and Shah [12] in a another study, developed Predicting stock market index using fusion of machine learning techniques. Their main focus was to predict the future value of the stock market index. They conducted their studies on the historical data related to CNX Nifty and S\&P BSE Sensex from the Indian stock market in the periods of one, ten, 15 and 30 days. In their study, two methods of machine learning was used, In the first method, classification models were used individually, and in the second method, a two-step algorithm was used which, in the first step, the future values of the index value were predicted by the SVR, and these values were considered as inputs of classification models. The results showed that in the two-step method, the amount of errors has decreased. The models used in their paper to predict were ANN, SVR, and Random Forest.

Ballings and Van den Poel [13] together evaluated multiple classifiers for stock price direction prediction. In their study, the results of ensemble learning methods, including Random Forest, AdaBoost and Kernel Factory, and individual learning, including Neural Networks, Logistic Regression, Support Vector Machines, and K-Nearest Neighbors, have been compared in prediction of stock prices. The results of this case study show that Random Forest has the best performance and SVM, Kernel Factory, and AdaBoost methods are in the following order.

Yang and Rao [14] worked on an Ensemble Model for Stock Price Movement Trend Prediction on Different Investing Periods. They used the ensemble learning method called SRAVoting, which combines the 
results of the SVM, Random Forest and AdaBoost models. The inputs of the model include transaction data and technical indicators, and data are extracted from the Chinese stock market. The results showed that the proposed SRAVoting method offers higher predictive accuracy than SVM and Random Forest but does not necessarily have higher annual yields than SVM.

Zhang and Li [15] developed Stock trend prediction based on a new status box method and AdaBoost probabilistic support vector machine. In their study, they outlined the strategy of buying and selling the share according to the classification of the situation as follows:

High status class, Neutral status class and Low status class

If the stock price increases and the expected class have a lower probable output, then the price is likely to decrease and vice versa.

They used BPN, AdaBoost-GA-PWSVM for prediction models. The inputs included a daily stock price, and the data was as follows: 20 stocks from the Chinese market and 16 stocks from the NASDAQ market were chosen. The results of PSVM, BPN, and AdaBoost and GA-PWSVM methods are compared and the accuracy of the proposed method is higher and its G-means is lower than other methods.

Weng and Ahmed [16] developed Stock market one-day ahead movement prediction using disparate data sources. Their innovation has been in the data source, with a collection of online data scattered across the Internet, combined with traditional time series and technical indicators to provide a more up-to-date system for prediction. The methods used to predict was Decision tree, neural network, and support vector machine. Also, their article was a case study of Apple's shares in the NASDAQ market. The price data was collected from May 2012 to June 2015. The results showed that Apple's future price stock were up to $85 \%$ close to reality. The authors of this study has shown that the use of Google and Wikipedia data, diversified into databases, and the use of simple models (ANN and SVM combinations) of machine learning can provide a smart decision making tools.

Chen and Hao [17] developed a feature weighted support vector machine and K-nearest neighbor algorithm for stock market indices prediction. They developed the k-nearest neighbor techniques and support vector machine, in which the input characteristics of the methods was weighted by their importance, and the Shanghai and Shenzhen stock market indices was predicted using these methods and based on historical data. The result of the predictions has shown that the use of these two methods can be used in short and long-term forecasts.

Deep learning networks for stock market analysis and prediction: Methodology, data representations, and case studies, is the title of Chong and Han [18] study. By raw inputs that relate to stock returns of past periods, seven feature sets are produced using three methods to predict future stock returns. Input data is related to South Korean stock market. The results show that the proposed three-layer neural network method has a better predictive value when used in the self-correlation model.

In the last studies, the future trend of stock price was predicted with using neural network, support vector machine, random forest, $\mathrm{k}$-nearest neighbor, RBF, K-Means, regression, and ensemble learning algorithms. In some other studies, the value and future trends of the market index was predicted. The focus of those researches has been on individual and ensemble prediction models and their improvement.

The focus of this study is on three innovations:
We used a MCDM method to filter the input of machine learning algorithms and Ensemble learning. We also added a parameter to examine the impact of emotion and market excitement in the upcoming price trend. We determined the accuracy of technical indicators in terms of their performance in predicting price trends. Finally, we developed an Ensemble learning algorithm with an optimization method, and we used it to increase the output of individual learning.

The rest of the paper is organized as follows: Section 2 describes Methods, which includes the Formula of Input Values, Machine Learning and ensemble Learning Algorithms, and also the VIKOR Ranking Method. In section 3, we describe Results and data, Also, the results of all machine learning algorithms are compared with each other. Finally, in Section 4, we came to the conclusion. This conclusion is based on the results obtained in this study and all studies carried out in this area.

\section{Material and Methods}

\section{Method structure}

In this section, the method of calculating technical indicators is expressed. Also, the results of these indicators after the ranking by MCDM techniques are considered as input values of machine learning algorithms, Therefore, the method of calculating indicators and machine learning algorithms is discussed. In Figure 1 the structure of the method is described.

As shown in Figure 1, eight technical indicators that input the machine learning algorithms are presented below, and then we enter the MCDM discussion and machine learning.

Technical indicator: The formulas for technical indicators are presented in this section. These formulas are widely used by traders in financial markets. These indicators are as follows;

Moving-average (MA): This indicator includes several different moving averages, in this study we refer to three of them. These three moving averages are:

Simple Moving Average (SMA)

$\mathrm{EMA}_{\mathrm{n}}=\mathrm{p}_{\mathrm{n}} \frac{2}{\mathrm{~T}+1}+\mathrm{EMA}_{\mathrm{n}-1}\left(1-\frac{2}{\mathrm{~T}+1}\right)$

Exponential Moving Average (EMA)

$\mathrm{EMA}_{\mathrm{n}}=\mathrm{p}_{\mathrm{n}} \frac{2}{\mathrm{~T}+1}+\mathrm{EMA}_{\mathrm{n}-1}\left(1-\frac{2}{\mathrm{~T}+1}\right)$

In Equation 2, $\mathrm{p}_{\mathrm{n}}$ is the final price today (EMA calculation day) and $\mathrm{T}$ is the time period.

It should be noted that in order to start calculating this indicator, the first EMA is required, which is the first EMA of the moving average $\mathrm{T}$ of the previous period, which in this study, $\mathrm{T}$ is considered from the beginning to the end of the price data.

Weighted Moving Average (WMA)

WMA $=\frac{(\text { Close Price } * \mathrm{n}+\text { Close Price }(1) * \mathrm{n}-1+\ldots \text { Close Price }(\mathrm{n}-1) * 1)}{\left(\mathrm{n} * \frac{(\mathrm{n}+1)}{2}\right)}$

In Equation 3, $\mathrm{n}$ is the time period considered in this study according to the stock market of Iran is 26 days. 


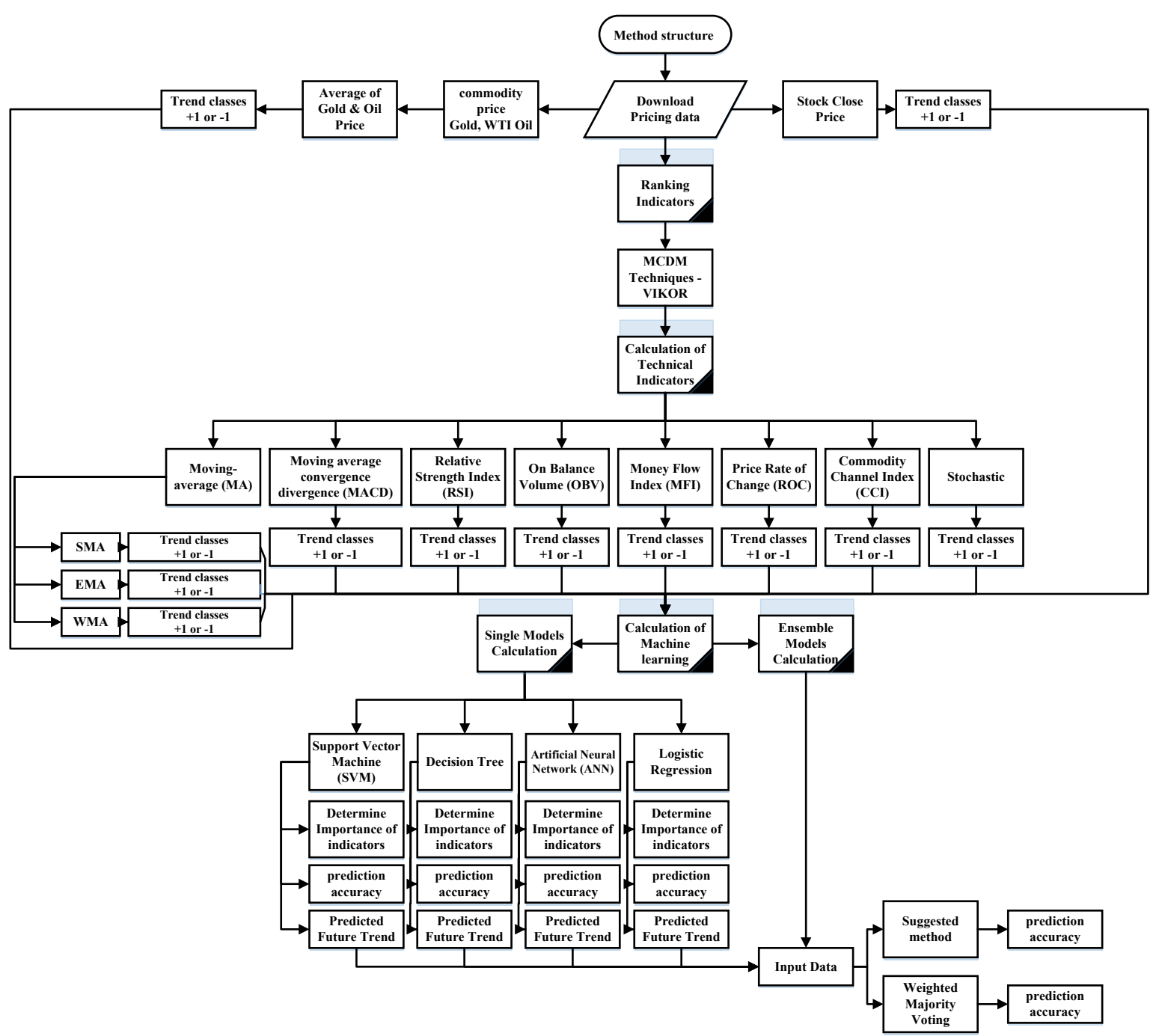

Figure 1: Structure of the proposed method.

Moving average convergence divergence (MACD): This indicator is in the category of oscillators that shows the overall trend of price movement through two moving averages. MACD is one of the easiest and most effective indicators of technical analysis used to measure financial instrument position. The MACD has three main components that we need to know;

Main Line or MACD Line: This line is a combination of two exponential moving averages, in other words, this line is the subtraction of the 26 day and 12 day exponential moving. It is worth noting that 26 and 12 are the default numbers of this index, we can change the numbers according to our need. The equation for these moving averages is shown in Equations 4 and 5. And in Equation 6, we see how to calculate the main line of the MACD

$$
\begin{aligned}
& \mathrm{SMA}_{12 \text { Days }}=\frac{\sum_{\mathrm{i}=1}^{\mathrm{n}=12} \text { ClosePrice Day }}{\mathrm{i}} \\
& \mathrm{n}=12 \\
& \mathrm{SMA}_{26 \text { Days }}=\frac{\sum_{\mathrm{i}=1}^{\mathrm{n}=26} \text { ClosePrice Day }}{\mathrm{n}=26}
\end{aligned}
$$

$$
\mathrm{MACD}_{\mathrm{i}=26}^{\mathrm{n}}=\mathrm{SMA}_{12 \text { Days }}-\mathrm{SM}
$$

Relative Strength Index

$$
\mathrm{RSI}=100-\frac{100}{1+\mathrm{RS}}
$$

In Equation 7, RS is a relative power parameter and equal to the result of the difference of the following two values:

- The first obtained average: The average daily profit ratio (the close price to the first price, if positive, otherwise, is zero) in the past two weeks.

- The first loss average: The average daily profit ratio (the close price to the first price, if negative, otherwise, is zero) in the past two weeks.

On balance volume (OBV): This indicator will visually assist the trader to closely monitor the flow of trading volumes and compare 
it with price movements. The volume of trading should grow in the direction of the price. The OBV structure is described in equations 8 to 10 .

If close price of day ${ }_{n}>$ close price of day $(\mathrm{n}-1)$, then $\mathrm{OBV}$ of day $\mathrm{n}_{\mathrm{n}}=\mathrm{OBV}$ of day $_{(\mathrm{n}-1)}+$ trading volume

If close price of day ${ }_{n}<$ close price of day $y_{(n-1)}$, then OBV of day $y_{n}=O B V$ of day $_{(\mathrm{n}-1)}$-trading volume

If close price of day ${ }_{n}=$ close price of day $y_{(n-1)}$, then OBV of day $y_{n}=O B V$ of day $\ln _{(\mathrm{n}-1)}$

It is important to note that the amount of the first $\mathrm{OBV}$ is equal to the trading volume of that day.

Money flow index (MFI): MFI is a technical analysis indicator that measures the rise and fall in prices over a period of time and estimates the entry of liquidity into the market. It also considers transaction volumes. In the following, we will review the calculation of this indicator;

Step 1: Calculate the average of lowest low, highest high and close price

Typical Price $=\frac{(\text { High }+ \text { Low }+ \text { Close })}{3}$

Step 2: multiplies the value of the first step in the volume of transactions

Money Flow=Typical Price $\times$ Volume

Step 3: Calculate the positive and negative values of the money flow as follows:

For a 14-day window:

- If the Typical Price is higher than the Typical Price of the previous day, then the positive flow rate is equal to the Money Flow amount.

- If the Typical Price is lower than the Typical Price of the previous day, then the negative flow rate is equal to the Money Flow amount.

Step 4: Calculate the money ratio by dividing the total 14-day positive cash flow into a total 14-day negative cash flow.

Step 5: Calculate the flow of money according to the equation 13

$$
\text { Money Flow Index }=\frac{100-100}{(1+\text { Money Ratio })}
$$

Rate of change (ROC): Prices in a cycle increase or decrease widely. These cyclic and alternate movements occur as a result of changes in the expectations of traders. If prices rise, ROC grows to and vice versa. The more the prices change, the more ROC will change. This indicator is calculated according to Equation 14

$$
\mathrm{ROC}=\frac{\text { Close Price }-\mathrm{n} \text { Close Price }}{\mathrm{n} \text { close price }}
$$

In equation 14 we have $\mathrm{n}$ which is the final price of 14 Days.

Commodity channel index (CCI): $\mathrm{CCI}$ is another popular indicator of financial markets. Despite the primary goal of this indicator, which determined new trends, it is now widely used to assess the current level of prices associated with its average. We describe the calculation of this
Indicator in Equation 15

$\mathrm{CCI}=\frac{\text { Typical Price }-\mathrm{n} \text { period SMA of Typical Price }}{0.015^{*} \text { Mean Deviation }}$

In Equation 15, the 0.015 value in the denominator attempts to limit the index output in the range of 100 to $100+$. Also "n period SMA of Typical price" is the deviation of 20 days average.

Average directional index (ADX): To calculate this indicator, it is first necessary to determine the positive and negative values of the guidance index. The $+\mathrm{DM}$ is the difference between the highest current price and the highest price of the day before and the -DM is the difference between the lowest current price and the lowest price of the day before. And the ADX trend line is obtained as equation 16;

$$
\mathrm{ADX}=\left[\mathrm{MA}\left[\frac{[(+\mathrm{DI})-(-\mathrm{DI})]}{[(+\mathrm{DI})+(-\mathrm{DI})]}\right] \times 100\right.
$$

Stochastic: The Stochastic oscillator is an indicator that is used to diagnose the direction of the price trend and the probable points of correction. The diagnosis is done by specifying the current price spot in the last price range, as the fixed prices in the bullish trend tend to be as high as possible, And vice versa. This indicator consists of two lines K\% and D\%, which are calculated in terms of Equations 17 and 18;

$$
\begin{aligned}
& \mathrm{K} \%=\left(\frac{\text { Close Price }- \text { Lowest Low }}{\text { Highest High }- \text { Lowest Low }}\right) \times 100 \\
& \text { D\%=3 Days Average of K\% }
\end{aligned}
$$

Converts outputs of indicators: The final values of the technical indicators are calculated according to the input data. And the output of these results has been converted into two bullish (positive 1) and bearish (negative 1) based on the following equation and as inputs to machine learning methods.

$$
\begin{aligned}
& \mathrm{T}_{1}=\text { Value of } \text { day }_{\mathrm{n}}-\text { Value of day } \\
& \mathrm{T}_{2}=5 \text { day Average of }\left(\mathrm{T}_{1}\right)
\end{aligned}
$$

Trend $=$ if $T_{2} \geq 0$ then, $(+1)$, other wise $(-1)$

Machine learning and optimization: Arthur Samuel [19], one of the leaders in the field of computer games and artificial intelligence, recorded the term "machine learning" in 1959. Machine learning, inspired by computational learning theory, examines and constructs algorithms that can be learned and predicted based on data. Such algorithms do not follow program commands. They model or predict input data from a Modeling. Machine learning is used in computational tasks where the design and programming of explicit algorithms with their proper function is difficult or impossible; some applications include filtering emails, identifying intruders or internal malware that are intended to infiltrate information, Optical character reader (OCR), learning rankings, and machine vision. In this study, we have used 4 individual Machine learning methods and two ensembles learning as follows.

Support vector machine (SVM): Support vector machines [2022] are powerful tools for data classification. By assigning data to two separate half-pages in the original space of the linear problem or in higher-dimensional spaces for nonlinear problems, tries to classify the data $[22,23]$ Even if they are not linearly detachable.

\section{SVM Algorithm:}

Classes are separated by the plate, after mapping data to a higher dimension, two data sets can be separated by line or plate. The primary 
objective function of the problem (Equation 20) is to find the function of the best line or plate data separator, the closest training data to the page is called the support vector.

$$
\begin{aligned}
& \min _{\lambda} \frac{1}{2} \sum_{\mathrm{i}=1}^{\mathrm{n}} \sum_{\mathrm{j}=1}^{\mathrm{n}} \lambda_{\mathrm{i}} \lambda_{\mathrm{j}} \mathrm{s}_{\mathrm{i}} \mathrm{s}_{\mathrm{j}} \mathrm{K}\left(\mathrm{y}_{\mathrm{i}}, \mathrm{y}_{\mathrm{j}}\right) \\
& \text { s.t } \sum_{\mathrm{i}=1}^{\mathrm{n}} \mathrm{s}_{\mathrm{i}} \lambda_{\mathrm{i}}=0, \\
& 0 \leq \lambda_{\mathrm{i}} \leq \mathrm{C} \mathrm{i}=1, \ldots, \mathrm{n}
\end{aligned}
$$

In equation $20, \mathrm{~K}$ is a kernel function as we have: $\left\langle\phi\left(\begin{array}{l}\mathrm{x}_{1} \\ \mathrm{x}_{2}\end{array}\right), \phi\left(\begin{array}{l}\mathrm{y}_{1} \\ \mathrm{y}_{2}\end{array}\right)\right\rangle=\left(1+\mathrm{x}_{1} \mathrm{y}_{1}+\mathrm{x}_{2} \mathrm{y}_{2}\right)^{2} \Rightarrow \mathrm{K}(\mathrm{x}, \mathrm{y})=\left(1+\mathrm{x}_{1} \mathrm{y}_{1}+\mathrm{x}_{2} \mathrm{y}_{2}\right)^{2}$

Decision tree: The decision tree allows us to predict or classify observations in the future. This method partly divides educational data in each step with goal of reducing impurities (Equation 22).

$$
I(D)=\frac{\left|D_{1}\right|}{|D|} I\left(D_{1}\right)+\frac{\left|D_{2}\right|}{|D|} I\left(D_{2}\right)
$$

In equation 22 , parameter $\mathrm{D}$ is the data set of node $t$, and $\mathrm{D}_{1}, \mathrm{D}_{2}$ is the data of the new first and second nodes.

Artificial neural network: In this study, a three-layer neural network was used to predict the error propagation algorithm [24]. The processes for calculating the neural network in this study are described in Equation 23 to 31. These steps include: rate $\eta$

Generate $\mathrm{V}$ and $\mathrm{W}$ weight matrix randomly and select the learning

Add training data to the input layer:

$$
Y_{j}=\sum_{i=1}^{d+1} V_{i j} x_{i} ; j=1,2, \ldots, r
$$

In equation $23, \mathrm{X}_{\mathrm{i}}$ is the value of the variable (neurons) of the input.

Calculates the output of the input layer based on the sigmoid activation function, as equation 24 ;

$\mathrm{f}(\mathrm{t})=\frac{1}{1+\mathrm{e}^{-\mathrm{Y}}} \Rightarrow \mathrm{f}(\mathrm{t})=\mathrm{y}$

Add output of input layer to hidden layer, as equation 24;

$\mathrm{Z}_{\mathrm{l}}=\sum_{\mathrm{i}=1}^{\mathrm{d}+1} \mathrm{~W}_{\mathrm{ij}} \mathrm{y} ; \mathrm{l}=1,2, \ldots, \mathrm{L}$

Output calculation is in the form of equation 26;

$\mathrm{f}(\mathrm{t})=\frac{1}{1+\mathrm{e}^{-\mathrm{Z}}} \Rightarrow \mathrm{f}(\mathrm{t})=\mathrm{z}$

Error calculation is in the form of equation 27;

$$
\mathrm{E}=\sum_{\mathrm{p}=1}^{\mathrm{p}_{\max }}\left(\frac{1}{2} \sum_{\mathrm{l}=1}^{\mathrm{L}}\left(\mathrm{d}_{\mathrm{pl}}-\mathrm{z}_{\mathrm{pl}}\right)^{2}\right)
$$

In equation $27, \mathrm{p}_{\max }$ is the number of training samples and $\mathrm{d}_{\mathrm{pl}}$ is the value of the next dimension of $\mathrm{p}$ sample.

Calculates the error signal for the output layer's neurons, in the form of equation 28 ;

$$
\delta\left(z_{1}\right)=\left(d_{1}-z_{1}\right) z_{1}\left(1-z_{1}\right) ; 1=1,2, \ldots, L
$$

Calculates the error signal for all hidden neurons, as equation 29;

$$
\delta\left(\mathrm{y}_{\mathrm{j}}\right)=\mathrm{y}_{\mathrm{j}}\left(1-\mathrm{y}_{\mathrm{j}}\right) \sum_{\mathrm{l}=1}^{\mathrm{L}} \mathrm{W}_{\mathrm{j} 1} \delta\left(\mathrm{z}_{1}\right) ; \mathrm{j}=1,2, \ldots, \mathrm{r}
$$

Update Weights Matrixes as equation 30 and 31;

$$
\begin{aligned}
& \mathrm{W}_{\mathrm{j} 1} \Rightarrow \mathrm{W}_{\mathrm{j} 1}+\eta \delta\left(\mathrm{z}_{1}\right) \mathrm{y}_{\mathrm{j}} ; \mathrm{j}=1,2, \ldots, \mathrm{r}+1 ; 1=1,2, \ldots, \mathrm{L} \\
& \mathrm{V}_{\mathrm{ij}} \Rightarrow \mathrm{V}_{\mathrm{ij}}+\eta \delta\left(\mathrm{y}_{\mathrm{j}}\right) \mathrm{x}_{\mathrm{i}} ; \mathrm{i}=1,2, \ldots, \mathrm{d}+1 ; \mathrm{j}=1,2, \ldots, \mathrm{r}
\end{aligned}
$$

Return to the stage of calculating the output of the input and the hidden layers until the condition of the stop

Logistic regression: In this study, the logistic regression binomial method has been used so that the negative class in the model is known as the zero and the positive one in the model known as the positive one. The calculation method is as follows:

$$
\mathrm{g}(\mathrm{p}(\mathrm{x}))=\operatorname{Ln}\left(\frac{\mathrm{p}(\mathrm{x})}{1-\mathrm{p}(\mathrm{x})}\right)=\beta_{0}+\beta_{1} \mathrm{x},
$$

After equating the two sides of equation 32, we have;

$$
\frac{\mathrm{p}(\mathrm{x})}{1-\mathrm{p}(\mathrm{x})}=\mathrm{e}^{\beta_{0}+\beta_{1} \mathrm{x}}
$$

So that $\mathrm{g}$ in the equation 32 is the logite function, which is equivalent to the linear regression function (equation 34). This is a real numeric function between zero and one:

$$
\operatorname{logit}(\mathrm{p})=\log \left(\frac{\mathrm{p}}{1-\mathrm{p}}\right)=\log (\mathrm{p})-\log (1-\mathrm{P})
$$

In equation 32, Ln represent the natural logarithm. $\mathrm{p}(\mathrm{x})$ Represent the possibility of the membership of the input value to each of the classes. The $\mathrm{p}(\mathrm{x})$ in equation 32 shows that the probability of the dependence of the input variable on one of the categories is equivalent to the value of the linear regression function. The results of this function are between zero and one. $\hat{a}_{0}$ is the separator of the equation of linear regression, $\hat{\mathrm{a}}_{1} \mathrm{x}$ is the regression coefficient, multiplied by the predictive value (input variable). And e also represents the exponential function.

Ensemble learning: This method involves a set of individual and trained machine learning models such as the neural network, decision tree, support vector machine and etc. The combination of outputs with each other, determines the result of the prediction and final classification [25]. These methods take advantage of the learning models and cover the weaknesses of the models and ultimately lead to more accurate predictions [26]. Based on the production strategy of the base model, Prediction by ensemble learning is divided into homogeneous and heterogeneous models. Heterogeneous models are predicted using the same training data and different learning algorithms or similar algorithms but with different parameters. In contrast, homogeneous models perform predictions with completely identical algorithms, but different data sets [27]. In other words, heterogeneous models, using the strengths and advantages of individual machine learning methods, are complementary to more precise predictions, while homogeneous models do the process of forecasting optimization with repeated training [27]. The models used in this study to combine the output of individual learning methods are heterogeneous models. 
Given that the predictive algorithm's performance has always been an attractive subject, it is possible to use ensemble learning methods in different domains [28], for example, in diagnosis of disease [29] prediction of system loading [30].

Many algorithms, including re-sampling techniques, such as bagging [31] or boosting [23], in which a subset of instructional data is randomized, is usually widely used by the replacement of all learning data to combine the output of individual learning models. Although these methods and other similar methods have effective results, they can be very costly in terms of calculations for uneducated learning data [32].

An important and influential factor in the development of ensemble learning models is the diversity and accuracy of individual classification methods. If the set of individual learning methods is highly correlated, then there will be little improvement in ensemble learning outcomes [33]. Therefore, it is advisable to use a variety of individual learning methods to improve the accuracy of ensemble learning. Many methods have been developed to reduce the size and increase the accuracy of ensemble learning [34]. Linear programming methods are also suggested for combining a large number of individual learning methods [33]. In this context, there are many two-objective models introduced. For example, we can reduce the output code error by simultaneously optimizing accuracy and diversity [35]. Similarly, an integer programming technique can be used for this purpose. The computational results of this approach have shown better performance [36], Some of the results of this approach are presented in [37] studies.

Weighted majority voting: In this study, the outputs of four learning machine (support vector machine models, decision tree, artificial neural network and logistic regression) are combined with the voting method (maximum votes). A striking point in the voting method is that the data should be labeled. The algorithm of this method is as equation 35 .

$$
\text { Majority Voting } \Rightarrow \sum_{\mathrm{t}=1}^{\mathrm{T}} \mathrm{d}_{\mathrm{t}, \mathrm{J}}(\mathrm{X})=\max _{\mathrm{j}=1}^{\mathrm{C}} \sum_{\mathrm{t}=1}^{\mathrm{T}} \mathrm{w}_{\mathrm{t}} \mathrm{d}_{\mathrm{t}, \mathrm{j}}
$$

In equation 35 we have $\mathrm{j}=1, \ldots, \mathrm{C}$ and $\mathrm{j}=1, \ldots, \mathrm{C}$ such that $\mathrm{T}=4$ is the number of classification methods (machine learning algorithms) and $\mathrm{C}=2$ is the number of classes.

Suggested method: In this study, an Ensemble Learning approach has been used to optimize diversity and dispersion [32]. Ensemble learning is expressed as a minimization problem. The general form of the minimization problem is as equation 36 :

$$
\begin{aligned}
& \min \mathrm{f}(\mathrm{w}) \frac{1}{2} \sum_{\mathrm{m}=1}^{\mathrm{M}}\left(\mathrm{w} \times \mathrm{x}_{\mathrm{m}}-\mathrm{y}_{\mathrm{m}}\right)^{2} \\
& \mathrm{C}_{1}:=\mathbb{R}_{+}^{\mathrm{N}} \\
& \mathrm{C}_{2}:=\left\{\mathrm{w}:=\left(\mathrm{w}^{\mathrm{n}}\right)_{\mathrm{n}=1}^{\mathrm{N}} \in \mathbb{R}^{\mathrm{N}}:\left\|\mathrm{w}_{1}\right\|: \sum_{\mathrm{n}=1}^{\mathrm{N}}\left|\mathrm{w}^{\mathrm{n}}\right| \leq \mathrm{t}_{1}\right\} \\
& \mathrm{C}_{3}:=\left\{\mathrm{w} \in \mathbb{R}_{+}^{\mathrm{N}}: \sum_{\mathrm{m}=1}^{\mathrm{M}}\left\{\left\langle\left[\mathrm{x}_{\mathrm{m}}\right] \cdot \mathrm{w}\right\rangle-\left\langle\mathrm{x}_{\mathrm{m}} \cdot \mathrm{w}^{2}\right\rangle\right\} \geq \mathrm{t}_{2}\right\} \\
& \mathrm{w} \in \mathrm{C}_{1} \cap \mathrm{C}_{2} \cap \mathrm{C}_{3}
\end{aligned}
$$

In the mathematical model, every data contains a label. $\mathrm{N}=4$ is the number of individual learning models $\mathrm{x}_{\mathrm{m}}$ and $\mathrm{K}$ is for the number of classes, so that $\mathrm{K}=2 . \mathrm{x}_{\mathrm{m}}$ is the output of the machine learning model for the sample $\mathrm{M}$ and $\mathrm{y}_{\mathrm{m}}$ is the corresponding label of the training data. $\left\|\mathrm{w}_{0}\right\| \leq \mathrm{t}_{1}$ is the decision variable whose optimal value will have the least error. According to the main goal, the $\operatorname{minf}(\mathrm{w})$ objective function attempts to reduce the least squared error of individual machine learning methods. The constraints of the problem are as follows:

The first constraint indicates that the value of the decision variable is positive.

The value of $\left\|\mathrm{w}_{0}\right\|$ in the second constraint is the flexibility parameter [38,39]. This parameter makes learning weights learn by cross-linking. This means that the output of individual learning combines to increase the efficiency of the result. The idea of flexibility is based on $1_{0}$-norm. Which states $\left\|\mathrm{w}_{0}\right\| \leq \mathrm{t}_{1}$, so that $\left\|\mathrm{w}_{0}\right\|$ refers to the number of non-zero elements of the $w$ vector. However, the optimization of this amount is difficult because of this, the distribution of $w$ considered as exponential distribution and it's represented as $t_{2}$, this is the term $l_{0}$-norm. The second constraint ensures that the results of all learning algorithms in ensemble learning will be used.

The $t_{2}$ value in the third constraint of equation 36 represents the variation parameter. So that:

$$
\left[x_{m}\right]=\left(\left(x_{m}^{n}\right)^{2}\right)_{n=1}^{N}=\left(\left(x_{m}^{1}\right)^{2} \cdot\left(x_{m}^{2}\right)^{2} \cdot \cdots \cdot\left(x_{m}^{N}\right)^{2}\right)^{T} \in \mathbb{R}_{+}^{N}
$$

This constraint ensures that all training data is used for prediction.

Ranking: We used MCDM ranking methods to filter machine learning inputs. Many methods are available for this purpose, which we considered MODM and VIKIOR methods for this purpose.

VIKOR: After collecting the questionnaires and ensuring the validity and reliability of the distributed questionnaire, the average scores assigned to each indicator are calculated according to the criteria (questionnaire questions) and a decision matrix (Table 1) is used to rank the indicators by the VIKOR method. It should be noted that in the decision matrix all indicators are considered positive.

$$
\begin{aligned}
& \mathrm{S}_{\mathrm{j}}=\sum_{\mathrm{i}=1}^{\mathrm{n}} \mathrm{W}_{\mathrm{i}} \cdot \frac{\mathrm{f}_{\mathrm{i}}^{*}-\mathrm{f}_{\mathrm{ij}}}{\mathrm{f}_{\mathrm{i}}^{*}-\mathrm{f}_{\mathrm{i}}^{-}} \\
& \mathrm{R}_{\mathrm{j}}=\max _{\mathrm{i}}\left[\mathrm{W}_{\mathrm{i}} \cdot \frac{\mathrm{f}_{\mathrm{i}}^{*}-\mathrm{f}_{\mathrm{ij}}}{\mathrm{f}_{\mathrm{i}}^{*}-\mathrm{f}_{\mathrm{i}}^{-}}\right]
\end{aligned}
$$$$
\text { VIKOR Algorithm: Calculate the } S_{j} \text { and } R_{j} \text { for } j=1 \ldots n
$$

So that $w_{i}$ is the weight of the $i$ criterion, $f_{i}^{-}$is the value of $j$ option in the $\mathrm{i}$ criterion, $\mathrm{f}_{\mathrm{i}}^{-}$is the lowest value of the $\mathrm{i}$ criterion in all options, $S$ is the highest value of the $i$ criterion. Also the $S_{j}$ is the mean of the normalized distance from the ideal point and $R_{j}$ is the maximum normalized distance from the ideal point.

$$
\begin{aligned}
& \text { The value of } j=1 \cdots \text { for } j=1 \cdots n \text { is: } \\
& Q_{j}=v \cdot \frac{S^{-}-S_{j}}{S^{-}-S^{*}}+(1-v) \cdot \frac{R^{-}-R_{j}}{R^{-}-R^{*}}
\end{aligned}
$$

So that:

${ }^{\text {o }} \mathrm{S}^{-}=\min _{\mathrm{j}} \mathrm{S}_{\mathrm{j}}{ }^{\mathrm{o}} \mathrm{S}^{-}=\min _{\mathrm{j}} \mathrm{S}_{\mathrm{j}}{ }^{\circ} \mathrm{R}^{-}=\min _{\mathrm{j}} \mathrm{R}_{\mathrm{j}}$ and $\mathrm{v}$ is the value that the decision maker puts for the mean, $1-\mathrm{v}$ is the value that the decision maker puts for maximum and the $\mathrm{Q}$ is value for optimizing the ranking calculation. 
Rank decision matrix options

The option with the lowest $\mathrm{Q}$ value is at the top. Finally, ten indicators ranking from one to ten are selected as inputs of individual and ensemble machine learning models.

\section{Results and Data}

In this section, the statistical sample and the result of the VIKOR method along with the results of individual and ensemble machine learning are presented. At the end of this section, machine learning results are compared (Table 2).

\section{Statistical sample}

In this study, the daily price data of three active symbols of Tehran Stock Exchange has been used. Data is collected from 2006 to 2018. Each active symbol includes a daily data set and status columns; date, starting price, close price, lowest price, highest price, volume of transactions, and closing price of the share on the previous day. Also, according to the opinion of Tehran stock market traders, the score information of technical indicators was completed and collected.

\section{Ranking results by VIKOR method}

Using the problem Decision Matrix (Table 1) the algorithm of the VIKOR method is written and the results are consistent with the Q index in Table 3. The top 10 ranking indicators are selected as inputs for machine learning models.

\section{Machine learning results}

Due to the large amounts of results, only the results of the Valghadr are displayed. The results of the individual and ensemble machine learning are respectively for the Valghadr symbol.

SVM algorithm prediction results: The results of the SVM model
On Valghadr symbol is written in the Tables 4-7. Also, the importance of indicators in terms of their performance in prediction is presented in Figures 2 and 3.

C\&R tree algorithm prediction results: The results of the SVM model On Valghadr symbol is written in the Tables 8 and 9. The importance of indicators in terms of their performance in prediction is presented in Figures 4-6. The trees are also drawn based on input data shown in Figures 4 and 7.

ANN algorithm prediction results: The results of the ANN model On Valghadr symbol is written in the Tables 10 and 11. Also, the importance of indicators in terms of their performance in prediction is presented in Figures 8 and 9.

Logistic regression algorithm prediction results: The results of the Logistic Regression model On Valghadr symbol is written in the Tables 12 and 13. Also, the importance of indicators in terms of their performance in prediction is presented in Figures 10 and 11.

Ensemble learning algorithm prediction results: The results of ensemble machine learning for each of the three symbols, based on the output of individual learning algorithms, are shown in Tables 14 and 15.

Comparing the results of ensemble learning: results of two ensemble learning methods for all three symbols are shown in Figure 12.

Comparing the results of all machine learning algorithms: The results of all learning methods for all three symbols are shown in Figures 13-15.

It is noted that all individual learning results for two other symbols are available and because we are limited in number of page, those results were not expressed in the article.

\begin{tabular}{|c|c|c|c|c|c|c|c|c|}
\hline Weight & 0.21739 & 0.21739 & 0.13 & 0.043478 & 0.087 & 0.2173913 & 0.0435 & 0.043478261 \\
\hline & Relation & Precision & Delay & Epidemic & Credit & sensitivity & Charm & realization \\
\hline Momentum & 3.67 & 3.59 & 3.34 & 3.167 & 3.25 & 3.5 & 3.25 & 3.5 \\
\hline RSI & 4 & 4.5 & 4.167 & 4.4167 & 4.167 & 4.5 & 4.4167 & 4.583 \\
\hline $\mathrm{CCl}$ & 3.34 & 4.416 & 3.67 & 4.4167 & 3.917 & 4.25 & 4.083 & 4.25 \\
\hline ADX & 2.41 & 3.167 & 2.5 & 3.167 & 2.417 & 2.83 & 2.84 & 2.167 \\
\hline MACD & 4.34 & 4.25 & 3.5 & 4.25 & 4.34 & 3.75 & 3.9167 & 4.25 \\
\hline OBV & 4 & 4.08 & 3.917 & 4.167 & 4.25 & 4.083 & 4.083 & 4.25 \\
\hline MFI & 4.17 & 4.08 & 3.75 & 4.25 & 4.084 & 4.083 & 4.34 & 4.084 \\
\hline EMA & 4.17 & 4.34 & 3.25 & 4.583 & 4.084 & 3.67 & 3.4167 & 4.25 \\
\hline SMA 20Days & 4.08 & 3.75 & 3.417 & 4.167 & 4.167 & 3.75 & 3.34 & 4.167 \\
\hline WMA 26Days & 4.167 & 3.58 & 3.583 & 4.167 & 4.084 & 3.67 & 3.4167 & 4.083 \\
\hline Stochastic & 4.25 & 4.4167 & 3.917 & 4.67 & 4.583 & 4.167 & 4.083 & 4.5 \\
\hline ROC & 3.34 & 3.34 & 3.083 & 3.75 & 3.84 & 3.4167 & 3.25 & 3.67 \\
\hline
\end{tabular}

Table 1: Decision Matrix, is based on market participants' comments.

\begin{tabular}{|c|c|c|c|c|c|c|}
\hline Row & Symbol & Company Name & Category & Market & Start date & End date \\
\hline 1 & Kasra & Ardakan Industrial Ceramics & Ceramic & \multirow{3}{*}{$\begin{array}{l}\text { TSE(Tehran Stock } \\
\text { Exchange) }\end{array}$} & \multirow{3}{*}{ August 1, 2006} & \multirow{3}{*}{ January 24, 2018} \\
\hline 2 & valghadr & Ghadir car leasing & Other financial intermediaries & & & \\
\hline 3 & kmanganez & Manganese mines of Iran & Extraction of metal & & & \\
\hline
\end{tabular}

Table 2: Data sets, includes the symbol of the active companies in the TSE and the time series of collected data. 
Citation: Emami SS (2018) Predicting Trend of Stock Prices by Developing Data Mining Techniques with the Aim of Gaining Profit. J Account Mark 7: 304. doi: 10.4172/2168-9601.1000304

\begin{tabular}{|c|c|c|}
\hline Row & Option (indicator) & $\begin{array}{c}\text { distance from the } \\
\text { negative ideal(Q) }\end{array}$ \\
\hline $\mathbf{1}$ & RSI & 0 \\
\hline $\mathbf{2}$ & CCl & 0.21326 \\
\hline $\mathbf{3}$ & Stochastic & 0.22292 \\
\hline $\mathbf{4}$ & MFI & 0.2941 \\
\hline $\mathbf{5}$ & OBV & 0.33684 \\
\hline $\mathbf{6}$ & MACD & 0.38597 \\
\hline $\mathbf{7}$ & EMA & 0.42902 \\
\hline $\mathbf{8}$ & SMA 20Days & 0.56822 \\
\hline $\mathbf{9}$ & WMA 26Days & 0.61563 \\
\hline $\mathbf{1 0}$ & ROC & 0.81497 \\
\hline $\mathbf{1 1}$ & ADX & 1 \\
\hline
\end{tabular}

Table 3: Indicator ranking results, based on the VKOR method and inputs of the decision matrix.

\begin{tabular}{|c|c|}
\hline Symbol & Valghadr \\
\hline Target variable & Close price trend \\
\hline Modeling method & SVM \\
\hline Modeling method & 11 \\
\hline number of input variables in the final model & 11 \\
\hline amount of landa's penalty parameter & 0.1 \\
\hline
\end{tabular}

Table 4: SVM model, valghadr (without average of oil \& Gold).

\begin{tabular}{|c|c|c|}
\hline Results & Numerical Value & Percent \\
\hline Correct & 2127 & 89.52 \\
\hline Wrong & 249 & 10.48 \\
\hline Total results (data rows) & 2376 & \\
\hline
\end{tabular}

Table 5: Accuracy of SVM model, valghadr (without average of oil \& Gold).

\begin{tabular}{|c|c|}
\hline Symbol & Valghadr \\
\hline Target variable & Close price trend \\
\hline Modeling method & SVM \\
\hline Modeling method & 12 \\
\hline number of input variables in the final model & 11 \\
\hline amount of landa's penalty parameter & 0.1 \\
\hline
\end{tabular}

Table 6: SVM model information, valghadr (with average of oil \& Gold).

\begin{tabular}{|c|c|c|}
\hline Results & Numerical Value & Percent \\
\hline Correct & 1165 & 85.35 \\
\hline Wrong & 200 & 14.65 \\
\hline Total results (data rows) & 1365 & \\
\hline
\end{tabular}

Table 7: Accuracy of SVM model-valghadr (with average of oil \& Gold).

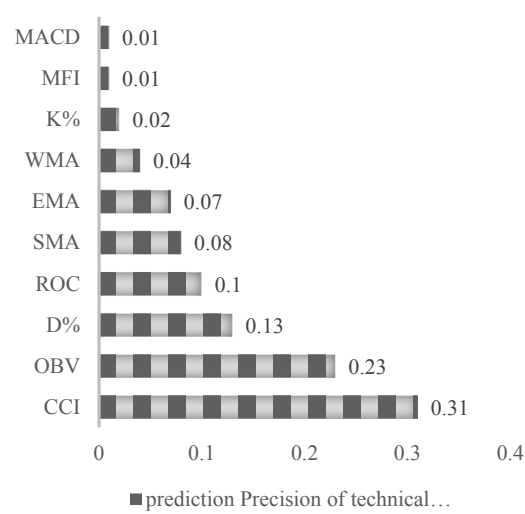

Figure 2: Prediction precision of technical indicators with SVM Model, Valghadr (without average of oil \& gold).

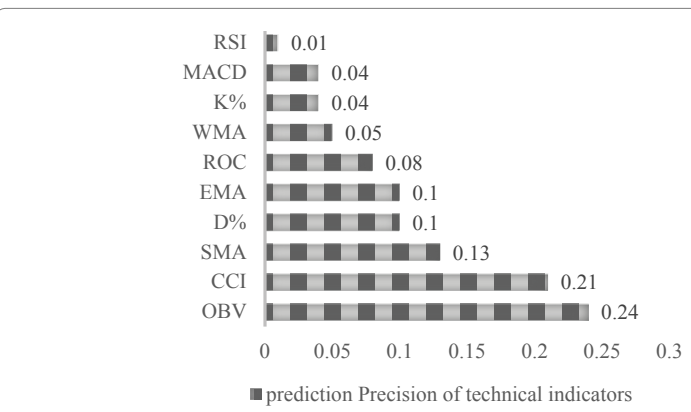

Figure 3: Prediction precision of technical indicators with SVM Model, valghadr (with average of oil \& gold).

\begin{tabular}{|c|c|c|}
\hline Results & Numerical Value & Percent \\
\hline Correct & 2025 & 85.23 \\
\hline Wrong & 351 & 14.77 \\
\hline Total results (data rows) & 2376 & \\
\hline
\end{tabular}

Table 8: Accuracy of C\&R Tree model-valghadr (without average of oil \& Gold).

\begin{tabular}{|c|c|c|}
\hline Results & Numerical Value & Percent \\
\hline Correct & 728 & 85.45 \\
\hline Wrong & 124 & 14.55 \\
\hline Total results (data rows) & 852 & \\
\hline
\end{tabular}

Table 9: Accuracy of C\&R Tree model,valghadr (With average of oil \& Gold).

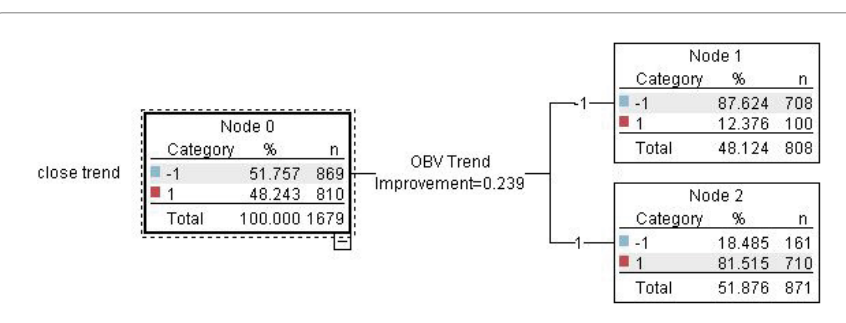

Figure 4: Decision tree, valghadr (without average of oil \& gold).

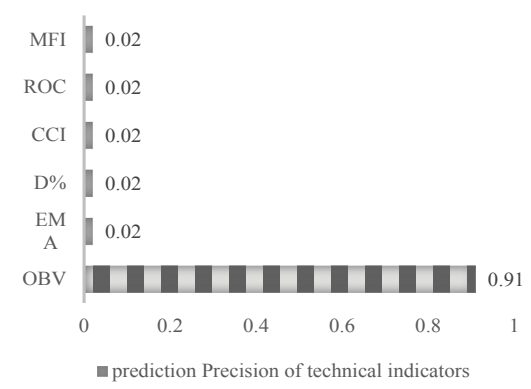

Figure 5: Prediction precision of technical indicators with C\&R Model, valghadr (without average of oil \& gold).

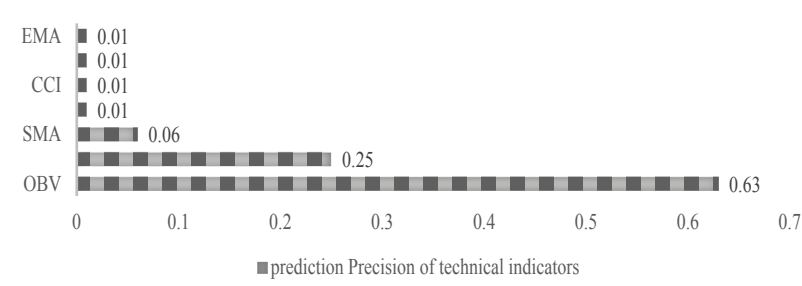

Figure 6: Prediction precision of technical indicators with C\&R Model, Valghadr (with average of oil \& gold). 
Citation: Emami SS (2018) Predicting Trend of Stock Prices by Developing Data Mining Techniques with the Aim of Gaining Profit. J Account Mark 7: 304. doi: 10.4172/2168-9601.1000304

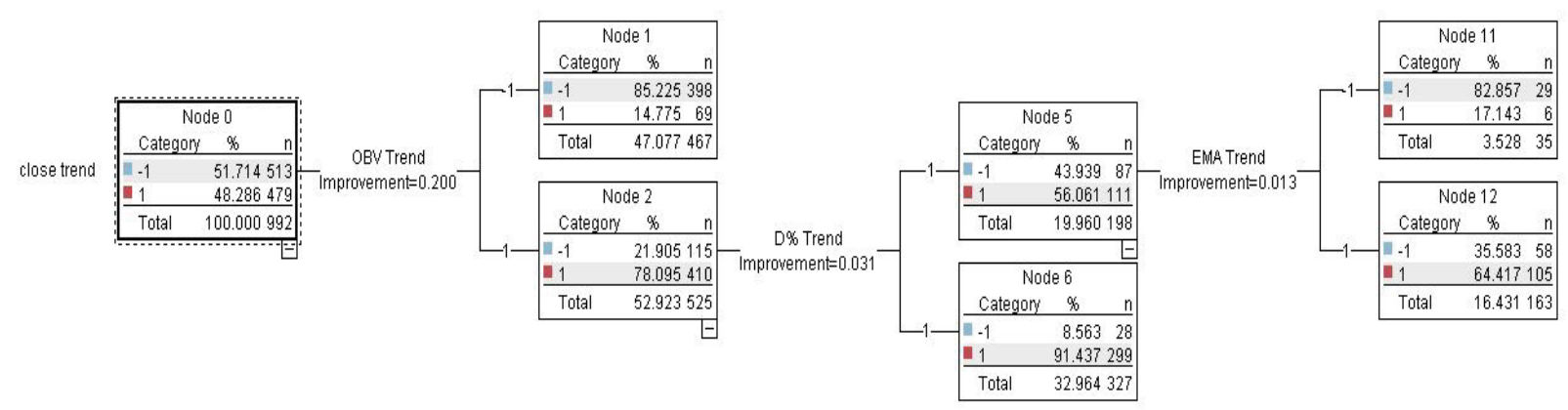

Figure 7: Decision tree, valghadr (with average of oil \& gold).

\begin{tabular}{|c|c|c|}
\hline Results & Numerical Value & Percent \\
\hline Correct & 2,103 & 88.51 \\
\hline Wrong & 273 & 11.49 \\
\hline Total results (data rows) & 2,376 & \\
\hline
\end{tabular}

Table 10: Accuracy of ANN model,valghadr (Without average of oil \& Gold).

\begin{tabular}{|c|c|c|}
\hline Results & Numerical Value & Percent \\
\hline Correct & 1,168 & 85.57 \\
\hline Wrong & 197 & 14.43 \\
\hline Total results (data rows) & 1,365 & \\
\hline
\end{tabular}

Table 11: Accuracy of ANN model,valghadr (With average of oil \& Gold).

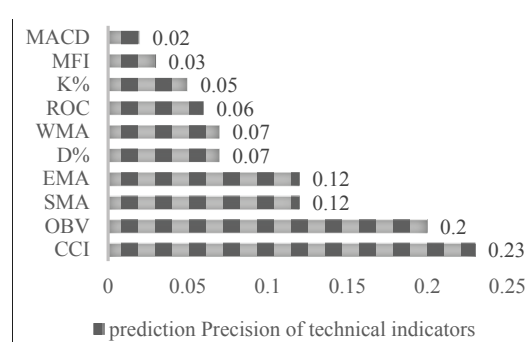

Figure 8: Prediction precision of technical indicators with ANN model, Valghadr (without average of oil \& gold).

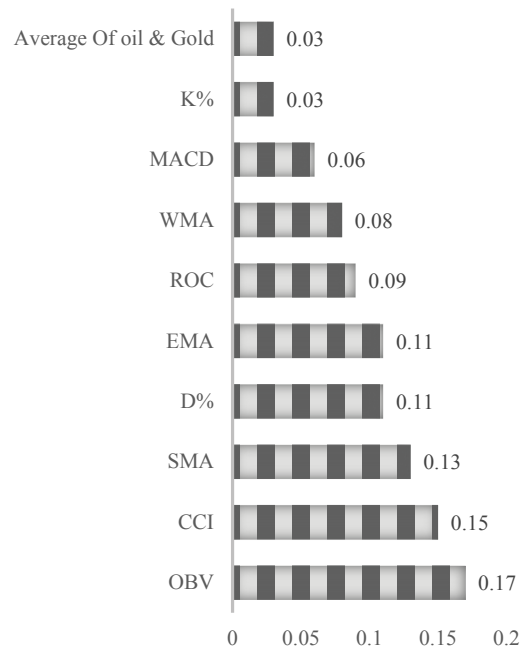

- prediction Precision of technical indicators

Figure 9: Prediction precision of technical indicators with ANN model, valghadr (with average of oil \& gold).

\begin{tabular}{|c|c|c|}
\hline Results & Numerical Value & Percent \\
\hline Correct & 2124 & 89.39 \\
\hline Wrong & 252 & 10.61 \\
\hline Total results (data rows) & 2376 & \\
\hline
\end{tabular}

Table 12: Accuracy of regression logistic model,valghadr (Without average of oil \& Gold).

\begin{tabular}{|c|c|c|}
\hline Results & Numerical Value & Percent \\
\hline Correct & 1.165 & 85.35 \\
\hline Wrong & 200 & 14.65 \\
\hline Total results (data rows) & 1,365 & \\
\hline
\end{tabular}

Table 13: Accuracy of regression logistic model,valghadr (With average of oil \& Gold).

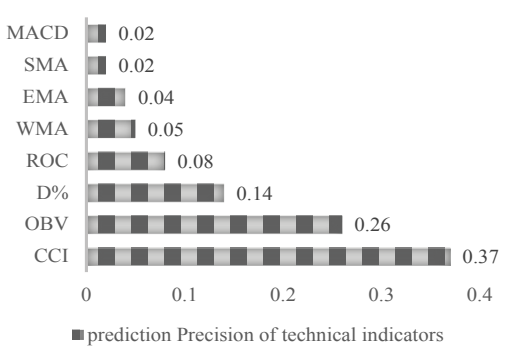

Figure 10: Prediction precision of technical indicators with logistic regression model, valghadr (without average of oil \& gold).

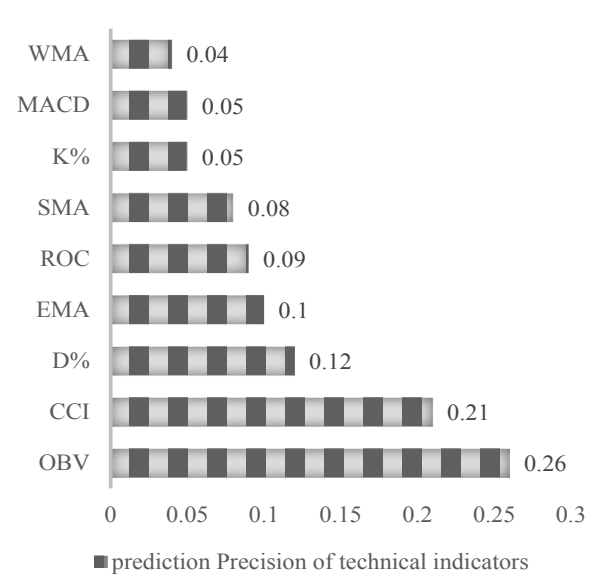

Figure 11: Prediction precision of technical indicators with logistic regression model, Valghadr (with average of oil \& gold). 
Citation: Emami SS (2018) Predicting Trend of Stock Prices by Developing Data Mining Techniques with the Aim of Gaining Profit. J Account Mark 7: 304. doi: 10.4172/2168-9601.1000304

Page 11 of 12

\begin{tabular}{|c|c|c|c|}
\hline \multirow{2}{*}{ Symbol } & Results & $\begin{array}{c}\text { Numerical } \\
\text { Value }\end{array}$ & Percent \\
\hline \multirow{3}{*}{ Valghadr } & Correct & 2,124 & 89.39 \\
\cline { 2 - 4 } & Wrong & 252 & 10.61 \\
\cline { 2 - 4 } & Total results (data rows) & 2,376 & \\
\hline \multirow{2}{*}{ Kasra } & Correct & 1,348 & 89.33 \\
\cline { 2 - 4 } & Wrong & 161 & 10.67 \\
\cline { 2 - 4 } & Total results (data rows) & 1,509 & \\
\hline \multirow{3}{*}{ Kmanganez } & Correct & 2,015 & 91.93 \\
\cline { 2 - 4 } & Wrong & 177 & 8.07 \\
\cline { 2 - 4 } & Total results (data rows) & 2,192 & \\
\hline
\end{tabular}

Table 14: Accuracy of weighted majority voting model (without average of oil \& Gold).

\begin{tabular}{|c|c|c|c|}
\hline \multirow{2}{*}{ Symbol } & Results & Numerical Value & Percent \\
\hline \multirow{3}{*}{ Valghadr } & Correct & 2,124 & 89.41 \\
\cline { 2 - 4 } & Wrong & 252 & 10.60 \\
\cline { 2 - 4 } & Total results (data rows) & 2,376 & \\
\hline \multirow{3}{*}{ Kasra } & Correct & 1,290 & 85.48 \\
\cline { 2 - 4 } & Wrong & 219 & 14.51 \\
\cline { 2 - 4 } & Total results (data rows) & 1,509 & \\
\hline \multirow{3}{*}{ Kmanganez } & Correct & 1,984 & 90.52 \\
\cline { 2 - 4 } & Wrong & 280 & 12.77 \\
\cline { 2 - 4 } & Total results (data rows) & 2,192 & \\
\hline
\end{tabular}

Table 15: Accuracy of suggested model (without average of oil \& Gold).

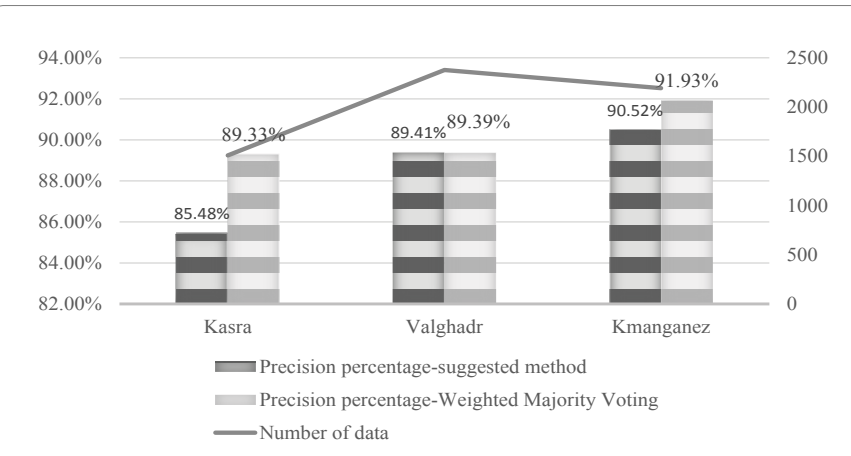

Figure 12: Ensemble learning results compare for three symbols (without average of oil \& gold).

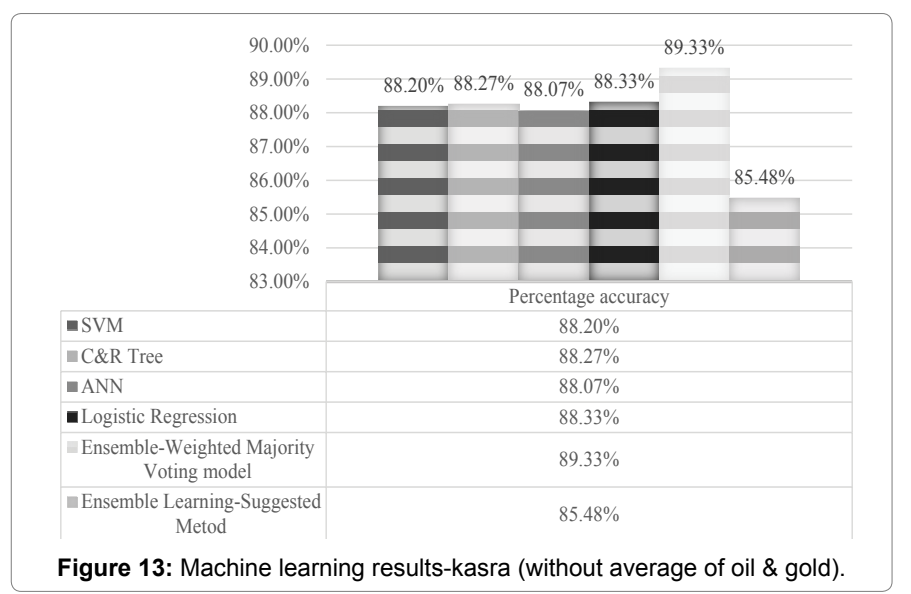

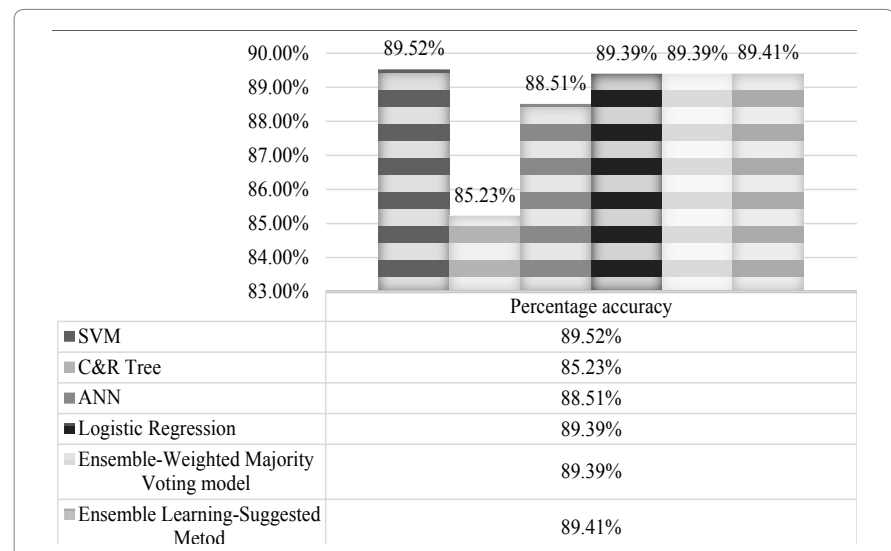

Figure 14: Compare machine learning results, valghadr (without average of oil \& gold).

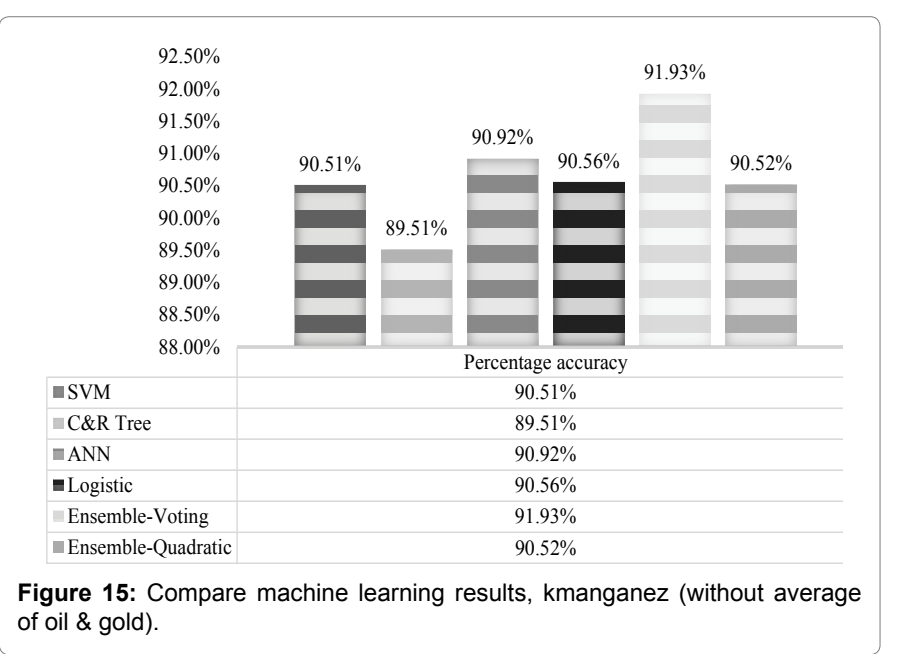

\section{Conclusion}

In this study, an introduction of formation and importance of the subject was presented and continued by presenting the research background in the field of technical analysis, existing research gaps and machine learning algorithms. Then, the popular technical analysis indicators according to opinion of Tehran stock market traders scored, and the decision matrix was formed, accordingly, the indicators were ranked by VIKOR for further studies.

Throughout the research process, the idea emerged that the how much id impact of global market excitement on the case study stocks? Therefore, the average of crude oil and gold close price trend was also considered as the input of the study.

Indicator values were considered as input variables after converting to trend (Bullish \& Bearish Trend) for four individual machine learning algorithms (support vector machine, decision tree, artificial neural network and logistic regression) and the trend of close price considered as the target variable. In each of these four algorithms, the outcomes of the upcoming trend were predicted with respect to inputs. Also, given the precision of prediction, the importance of each technical indicator was determined. It is worth noting that the trend of gold \& crude oil 
close price had the least impact on future case study stock price trends.

Also, among the technical indicators, the results of support vector machine, logistic regression and artificial neural network models showed that the CCI, OBV, SMA and EMA indicators are more important. The results of the decision tree decisively placed the importance of OBV in the highest. Also, the accuracy of machine learning algorithms was estimated to be higher than $90 \%$.

To reduce prediction error and increase accuracy we combined ensemble learning with non Linear programming method. This algorithm was introduced and solved as a nonlinear convex mathematical model. The results of this method showed improved accuracy, but the accuracy of the proposed Ensemble study approach was very close to the Weighted Majority Voting model, so with increasing data volume, we saw an increase in the accuracy of the proposed Ensemble Learning approach.

In this research, instead of using one symbol, the rules was simultaneously implemented on a stock portfolio with three active symbol of TSE, And the probability of non-random results being reduced.

\section{References}

1. Brock W, Lakonishok J, LeBaron B (1992) Simple technical trading rules and the stochastic properties of stock returns. J Finance 47: 1731-1764.

2. Baumol WJ, Heim P, Malkiel BG, Quandt RE (1973) Efficiency of corporate investment: reply. The Review of Economics and Statistics 55: 128-131.

3. Park $\mathrm{CH}$, Irwin SH (2004) The profitability of technical analysis: A review. Pp 106.

4. Charkha PR (2008) Stock price prediction and trend prediction using neural networks. ICETET Pp: 592-594.

5. Teixeira LA, Oliveira de ALI (2009) Predicting stock trends through technical analysis and nearest neighbor classification, Systems, IEEE International Conference on Systems, Man and Cybernetics Pp: 3094-3099.

6. Yeh CY, Huang CW, Lee SJ (2011) A multiple-kernel support vector regression approach for stock market price forecasting. Expert Systems with Applications 38: $2177-2186$.

7. Son $\mathrm{Y}$, Noh $\mathrm{Dj}$, Lee J (2012) Forecasting trends of high-frequency KOSPI200 index data using learning classifiers. Expert Systems with Applications 39: 11607-11615.

8. Booth A, Gerding E, Mcgroarty F (2014) Automated trading with performance weighted random forests and seasonality. Expert Systems with Applications 41: 3651-3661.

9. Di X (2014) Stock Trend Prediction with Technical Indicators using SVM.

10. Nayak RK, Mishra D, Rath AK (2015) A Naïve SVM-KNN based stock marke trend reversal analysis for Indian benchmark indices. Applied Soft Computing 35: $670-680$

11. Patel J, Shah S, Thakkar P, Kotecha K (2015) Predicting stock and stock price index movement using trend deterministic data preparation and machine learning techniques. Expert Systems with Applications 42: 259-268.

12. Patel J, Shah S, Thakkar P, Kotecha K (2015) Predicting stock market index using fusion of machine learning techniques. Expert Systems with Applications 42: 2162-2172.

13. Ballings M, Van den Poel D, Hespeels N, Gryp R (2015) Evaluating multiple classifiers for stock price direction prediction. Expert Systems with Applications 42: 7046-7056.

14. Yang J, Rao R, Hong P, Ding P (2016) Ensemble Model for Stock Price Movement Trend Prediction on Different Investing Periods. IEEE CIS Pp: 358-361.

15. Zhang Xd, Li A, Pan R (2016) Stock trend prediction based on a new status box method and AdaBoost probabilistic support vector machine. Applied Sof Computing 49: 385-398.

16. Weng B, Ahmed MA, Megahed FM (2017) Stock market one-day ahead movement prediction using disparate data sources. Expert Systems with Applications 79: 153-163.

17. Chen Y, Hao Y (2017) A feature weighted support vector machine and K-nearest neighbor algorithm for stock market indices prediction. Expert Systems with Applications 80: 340-355

18. Chong E, Han C, Park FC (2017) Deep learning networks for stock marke analysis and prediction: Methodology, data representations, and case studies. Expert Systems with Applications 83: 187-205.

19. Samuel AL (1959) Some studies in machine learning using the game of checkers. IBM J Res and Development 3: 210-229.

20. Burges CJ (1998) A tutorial on support vector machines for pattern recognition Data mining and knowledge discovery 2: 121-167.

21. Cherkassky V, Mulier F (1998) Learning from Data: Concepts, Theory, and Methods.

22. Bradley P, Mangasarian OL (2000) Massive data discrimination via linear support vector machines. Optimization methods and software 13: 1-10.

23. Schapire RE (1999) A brief introduction to boosting. 2: 1401-1406.

24. Karray FO, De Silva CW (2004) Soft computing and intelligent systems design: theory, tools, and applications.

25. Opitz DW, Maclin R (1999) Popular ensemble methods: An empirical study. J Arti Intell Res 11: 169-198.

26. Fan C, Xiao F, Wang S (2014) Development of prediction models for nextday building energy consumption and peak power demand using data mining techniques. Applied Energy 127: 1-10.

27. Wang Z, Wang Y, Srinivasan RS (2018) A novel ensemble learning approach to support building energy use prediction. Energy and Buildings 159: 109-122.

28. Giacinto G, Roli F (2001) Design of effective neural network ensembles for image classification purposes. Image and Vision Computing 19: 699-707.

29. Tan AC, Gilbert D (2003) Ensemble machine learning on gene expression data for cancer classification. Appl Bioinformatics 2: 75-83.

30. Siwek K, Osowski S (2009) Szupiluk R Ensemble neural network approach for accurate load forecasting in a power system. International Journal of Applied Mathematics and Computer Science 19: 303-315.

31. Breiman L (1996) Bagging predictors. Machine learning 24: 123-140.

32. Hayashi $\mathrm{Y}$, liduka $\mathrm{H}$ (2018) Optimality and convergence for convex ensemble learning with sparsity and diversity based on fixed point optimization. Neurocomputing 273: 367-372.

33. Zhang L, Zhou WD (2011) Sparse ensembles using weighted combination methods based on linear programming. Pattern Recognition 44: 97-106.

34. Martínez-Muñoz G, Hernández-Lobato D, Suárez A (2009) An analysis of ensemble pruning techniques based on ordered aggregation. IEEE Transactions on Pattern Analysis and Machine Intelligence 31: 245-259.

35. Özöğür-Akyüz S, Windeatt T, Smith R (2015) Pruning of Error Correcting Output Codes by optimization of accuracy-diversity trade off. Machine Learning 101: 253-269.

36. Zhang Y, Burer S, Street WN (2006) Ensemble pruning via semi-definite programming. J Mach Learn Res 7: 1315-1338.

37. Kim Y, Street WN, Menczer F (2002) Meta-evolutionary ensembles. IEEE Pp: 2791-2796.

38. Yin XC, Huang K, Hao HW, lqbal K, Wang ZB (2014) A novel classifier ensemble method with sparsity and diversity. Neurocomputing 134: 214-221.

39. Yin XC, Huang K, Yang C, Hao HW (2014) Convex ensemble learning with sparsity and diversity. Information Fusion 20: 49-59. 